\title{
Surgical Oncology Trials and Surgeons in the Real World!
}

\author{
Waddah B. Al-Refaie, MD, FACS ${ }^{1}$, Peter W. P. T. Pisters, MD, FACS ${ }^{2}$, and David A. Rothenberger, MD, FACS ${ }^{3}$ \\ ${ }^{1}$ Division of Surgical Oncology, Department of Surgery, University of Minnesota and Minneapolis VAMC, Minneapolis, \\ MN; ${ }^{2}$ Department of Surgical Oncology, The University of Texas M. D. Anderson Cancer Center, Houston, TX; \\ ${ }^{3}$ Department of Surgery, University of Minnesota, Minneapolis, MN
}

Randomized clinical trials (RCTs) are reputed to be critical to the everyday practice of surgery by providing high-quality evidence to guide, inform, and establish the standards of treatment for persons with cancer. ${ }^{1,2}$ RCTs are designed to minimize bias and equalize potential confounding effects of measured and unmeasured variables. To this date, RCTs remain the gold standard to assess the efficacy of alternative interventions, as enormous resources and time are expended to conceive, conduct, monitor, and complete cancer trials. The ultimate goal of this effort is to improve survival and functional outcomes of patients with cancer, but achieving this goal requires rapid adoption and wide-scale implementation of trial results into standard clinical practice.

Unfortunately, the hoped-for rapid, widespread dissemination of surgical oncology trial results into clinical practice often does not occur. ${ }^{3-5}$ Those exploring reasons for this failure have suggested that we lack the infrastructure, broad-based provider networks, and effective incentives and resources to drive fundamental changes in the delivery of cancer care in our fragmented, highly independent, fee-for-service health care system., ${ }^{4,7}$ However, are these the fundamental reasons for failure, or are there other factors to explain the wide discrepancy of accrual to cancer trials of less than 5\% in adults versus $70 \%$ in children? $?^{8,9}$

Many surgeons question the applicability of RCT results to their day-to-day practices, especially when fewer than $5 \%$ of adult cancer patients participate in surgical oncology trials. ${ }^{9}$ Most RCTs are conducted in university hospitals or major cancer referral centers, a potential source of bias.

(C) Society of Surgical Oncology 2010

Published Online: 15 April 2010

W. B. Al-Refaie, MD, FACS

e-mail: alref003@umn.edu
More important, volunteers for RCTs are generally more health conscious, more educated, more often Caucasian, financially more secure, and younger than cancer patients not participating in trials. ${ }^{10-12}$ By contrast, most adult oncology patients not participating in RCTs have multiple comorbidities (regardless of whether they are treated in large centers or community hospitals) and are older, more often from a minority group, and more often living on lower incomes with (for now) no or inadequate health insurance. ${ }^{11-13}$ Any of these factors could affect the generalizability of trial conclusions to the overall oncology population. For example, race-based variations have raised questions about the applicability of RCT findings to ethnic minorities. Federal policies and initiatives by the U.S. National Cancer Institute (NCI) have encouraged investigators to enroll a broader cohort of persons with cancer into clinical trials, but most surgical oncology RCTs continue to enroll younger persons with minimal comorbidities using strict inclusion, but generous exclusion, criteria.

Other factors that may interfere with surgeons' ability and willingness to accrue subjects to, or use results from, RCTs include: (1) patients' and surgeons' negative perceptions of being involved in or conducting experimental studies; (2) lack of support and clinical trial infrastructure in hospitals; (3) lack of appropriate compensation and incentives to participate; (4) fear that neoadjuvant or perioperative therapy trials, for example, may lead surgeons to lose control of their patients to their competitors; and (5) the current tight financial environment, which may not be conducive to participating in RCTs.

So, should anyone be surprised that many surgeons question the wisdom of generalizing conclusions from RCTs to their "real world" environment—one that is different from the controlled "ideal world" in which RCTs are conducted? $?^{5,9,14,15}$ The obvious challenge to oncology leaders is therefore to implement more trials that better 
reflect "real world" environments-but how do we do that? NCI-sponsored surgical oncology trials should and could accrue more participants by (1) broadening inclusion criteria so that typical persons with cancer of the "real world" can take part, (2) engaging more surgeons, and (3) reaching out to more health care systems. It is no longer feasible or appropriate to leave RCTs to major cancer or academic centers. Without broader trial participation of adults with cancer, we cannot hope to achieve the marked improvement in survival reported for children with cancer- $70 \%$ of whom participate in RCTs. ${ }^{16}$ Without such a concerted effort, practicing surgeons will continue to extrapolate results of RCTs that they believe may (or may not) apply to their daily clinical practice.

ACKNOWLEDGMENT Supported by The 2008 Veterans of Foreign Wars and Ladies Cancer Research Center Endowment Fund.

\section{REFERENCES}

1. Brennan MF. Commentary: randomized controlled trials. Surg Oncol Clin N Am. 2010;19:xix-xx.

2. Meyer RM. Generalizing the results of cancer clinical trials. $J$ Clin Oncol. 2010;28:187-9.

3. Brooks AD, Karpoff HM, Sulimanoff I, Coit D, Brennan MF, Jaques DP. The search for level I evidence in solid-tumor oncology. Ann Surg Oncol. 2001;8:638-43.

4. Elting LS, Cooksley C, Bekele BN, Frumovitz M, Avritscher EB, Sun C, et al. Generalizability of cancer clinical trial results: prognostic differences between participants and nonparticipants. Cancer. 2006;106:2452-8.

5. Rothenberger DA. Evidence-based practice requires evidence. $\mathrm{Br}$ J Surg. 2004;91:1387-8.
6. Dilts DM, Sandler AB. Invisible barriers to clinical trials: the impact of structural, infrastructural, and procedural barriers to opening oncology clinical trials. J Clin Oncol. 2006;24:4545-52.

7. Swanson GM, Bailar JC, 3rd. Selection and description of cancer clinical trials participants-science or happenstance? Cancer. 2002;95:950-9.

8. Lund MJ, Eliason MT, Haight AE, Ward KC, Young JL, Pentz RD. Racial/ethnic diversity in children's oncology clinical trials: ten years later. Cancer. 2009;115:3808-16.

9. Stewart JH, Bertoni AG, Staten JL, Levine EA, Gross CP. Participation in surgical oncology clinical trials: gender-, race/ethnicity-, and age-based disparities. Ann Surg Oncol. 2007;14:3328-34.

10. Gross CP, Filardo G, Mayne ST, Krumholz HM. The impact of socioeconomic status and race on trial participation for older women with breast cancer. Cancer. 2005;103:483-91.

11. Hutchins LF, Unger JM, Crowley JJ, Coltman CA, Jr, Albain KS. Underrepresentation of patients 65 years of age or older in cancer-treatment trials. N Engl J Med. 1999;341:2061-7.

12. Murthy VH, Krumholz HM, Gross CP. Participation in cancer clinical trials: race-, sex-, and age-based disparities. JAMA. 2004;291:2720-6.

13. Newman LA, Hurd T, Leitch M, Kuerer HM, Diehl K, Lucci A, et al. A report on accrual rates for elderly and minority-ethnicity cancer patients to clinical trials of the American College of Surgeons Oncology Group. J Am Coll Surg. 2004;199:644-51.

14. Al-Refaie WB, Habermann EB, Dudeja V, Vickers SM, Tuttle $\mathrm{TM}$, Jensen EH, et al. Extremity soft tissue sarcoma care in the elderly: insights into the generalizability of NCI trials. Ann Surg Oncol. 2010 [Epub ahead of print].

15. Al-Refaie WB, Parsons HM, Henderson WG, Jensen EH, Tuttle TM, Vickers SM, et al. Major cancer surgery in the elderly: results from the American College of Surgeons National Surgical Quality Improvement Program. Ann Surg. 2010;251:311-8.

16. Lamont EB, Landrum MB, Keating NL, Archer L, Lan L, Strauss $\mathrm{GM}$, et al. Differences in clinical trial patient attributes and outcomes according to enrollment setting. J Clin Oncol. 2010;28:215-21. 